\title{
Investigation of the Effect of Nano Particles on Visco-elastic Behaviour of CFRP Hybrid Nanocomposites
}

\author{
Shailesh D. Ambekar*, Vipin K. Tripathi ${ }^{\#}$ \\ "Department of Mechanical Engineering, Government College of Engineering, Aurangabad \\ \#Department of Mechanical Engineering, National Institute of Technology, Agartala
}

(Received 3 July 2020, accepted 13 October 2020)

https://doi.org/10.36224/ijes.130303

\begin{abstract}
The aim of the study is to do an experimental analysis and investigation of visco-elastic behaviour of CFRP hybrid nanocomposites, which contains the small percentage of nanoclay and nanoZnO particles mixed for the improvement in the various properties of the CFRP composites. Also there is try to focus on the combined effect of another variable, i.e., fiber angle of orientation along with changing the percentage of nano particles. A hand layup method followed by process of vacuum bagging was used to make the samples of composite. Dynamic mechanical analyzer (DMA) was used to inspect the dynamic mechanical properties of CFRP hybrid nanocomposite specimens with changing temperature. The OVAT analysis is carried out for three mentioned variables and studied effect of variables on the various visco elastic properties like flexural storage modulus, loss modulus, Glass transition temperature and $\tan \delta$ etc. It is found that due to the presence of nano particles there is tremendous change in the value of storage modulus, it gets almost doubled, i.e., 200\%because of the presence of nano particles. The experimental result also shows the positive effect on the loss modulus because of the nano particle contribution .Similarly there is considerable change in GTT(Glass transmission temperature) and change in length in DMA (Dynamic mechanical analysis ).
\end{abstract}

Keywords: Dynamic mechanical analysis (DMA); Visco elastic behaviour; hybrid nanocomposite; nanoclay; nanoZnO

\section{Introduction}

In the modern duration, fiber reinforced polymer is powerfully used in various components such as brakes, cams, gears and bearings etc, because of their and improved resistance to wear self-lubrication properties, lower friction. Polymer matrix composites are having higher strength to weight ratio, which is useful for various applications in an automobile, aerospace and various appliances. The manufacturing of material for a specific application depends on the variable like material expense, thickness, other working requirements and quality. The deficiency of polymers could be conquer effectively by using various special fillers like nano sized particles. The effects of nanoparticles addition on these properties have been broadly investigated. The addition of nanoparticles by weight of few percent can result in enhancement in mechanical properties significantly.. Carbon fibers composites give greater properties such as Young's modulus, higher strength, better thermal conductivity, and excellent electrical properties than other fibres. Many studies have focused on the incorporation of inorganic nanoparticles, which is a best approach to study the effect on visco elastic properties like storage modulus, loss modulus, GTT, $\tan \delta$ etc.

Shazed M.A. et al showed that The CNT are also helpful in development of mechanical properties of CFRP composites, when outside layer of CNT applied with different fiber orientations [1]. Rashmi, et al. and Li Chang et al. presented work on the 
improvement in the wear resistance of regular size and short carbon fiber composites in addition of nano particles. [2,3]. The astonishing mechanical, thermal and electrical properties of carbon nano tubes and nanoZnO have provoked researches to make use of them as a filler in composite in order to perk up the properties of the parent matrix[4,5]. Also many researchers have enlisted the effect of nanoparticles, fiber orientation etc, on the various carbon fiber composites by using dynamic mechanical analysis [6-11] With addition of nanoclay, the glass transition temperature can be increased as compared to neat $\mathrm{CF} / \mathrm{PPc}$ composite demonstrating improved heat resistance and improved themo mechanical properties with addition of organoclay as per the work of Mohamed $\mathrm{H}$. et al [12] In the study by Declan Carolana et al discussed that the nanoparticles are eagerly transferable to a toughness increase in the interlaminar fracture energy of the CFRP composite laminates [13]. M. B. A. Salam et al highlights on the effect of addition of multi walled carbon nano tubes in carbon fiber, epoxy composites, which end results in improvement of the thermo mechanical properties of the composites [14,15]. Sasan Nouranian, et al. has done the optimization of the nano composites for study their consequence in DMA [16]. V.K. Tripathi and N. S. Kulkarni, worked on optimal design comprehensive procedure of a composite laminate taking various parameters [17]U.V Hambire, V.K. Tripathi et al, have done the evaluation and optimization of dental composites for mechanical properties, and Tripathi V.K., et al, enlisted orderly procedure to get best possible optimum condition of composition for friction liners material [18-20]. Likewise it is also studied that carbon nano fibres, natural nano banana particles and nanoclay having stronger effect on the mechanical and viscoelastic properties of the composites as shown by researchers in their respective studies[21-23] Yasser Rostamiyan et al,[24-26] mixed epoxy resin with nanoclay as nanoparticle in the glass fiber reinforcement and studied its effects on mechanical properties, and found that new nanocomposite possesses improved mechanical properties like flexural strength ,tensile and impact These studies are carried out using the response surface methodology for the design of experiments. R. Satheesh Raja et al have studied effective improvement in the mechanical properties of GFRP composites with the implementation of micro fly ash [27]. In this paper there is experimental OVAT analysis of the Visco elastic behaviour in the Dynamic mechanical analysis (DMA) of the CFRP hybrid nano composite is presented. The combined effect of the three variables like weight percentage of nano clay and nano Zno particles and orientation angle of fiber is studied in DMA of CFRP nano composites. The OVAT analysis is carried out for three mentioned variables and studied effect of variables on the various visco elastic properties like flexural storage modulus, loss modulus, Glass transition temperature and $\tan \delta$ etc. It is found that due to the presence of nano particles there is tremendous change in the value of storage modulus, it gets almost doubled ie $200 \%$ because of the presence of nano particles. The experimental result also shows the positive effect on the loss modulus because of the nano particle contribution .Similarly there is considerable change in GTT(Glass transmission temperature) and change in length in DMA(Dynamic mechanical analysis ).
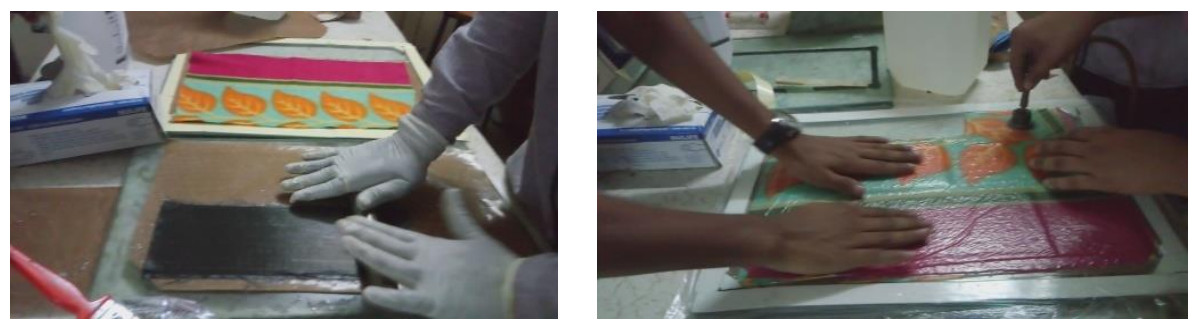

Figure 1: (a) Hand Lay up of CFRP,(b) Vacuum Bagging 


\section{Experimental}

\subsection{Details of material}

For the experiment in this assessment CFRP epoxy composites treat as controlled sample. The unidirectional carbon fabrics having standard modulus $3 \mathrm{~K}$ of $200 \mathrm{GSM}$, code HCU200. The resin named Hinpoxy C, which is Bisphenol -A based liquid resin beside with the amine modified hardener known as Hinpoxy hardener- $\mathrm{B}$ is a colorless, and small viscosity liquid with stoichiometric ratio of $A: B=10: 3$ was used. Resins, hardener with carbon fiber, supplied from the Hindoostan Mills Ltd. Mumbai, India. The nanoclay was montmorillonite, modified surface with layers of Aluminosillicate (approximately thickness of $1 \mathrm{~nm}$ ), and SpGra. 2.6. Zinc oxide - ZnO nanoparticles, with Purity of $99.9 \%$, SSA: 20-60 m2/g, with Particles Size: 30-50nm, Morphology: nearly spherical, True density: $6 \mathrm{~g} / \mathrm{cm} 3$ density for Bulk: $0.28-0.48 \mathrm{~g} / \mathrm{cm} 3$ were used, supplied from Nano Research Lab. Jamshedpur, (Jharkhand),India.

\subsection{Fabrication of composites}

CFRP hybrid nanocomposites laminates were made-up by using hand layup method(as shown in Fig.1.(a) followed by process of vacuum bagging(as shown in Fig. 1.(b) ). The epoxy resin system is a Diglycidyl ether of Bisphenol A (DGEBA) mixed with 1,3phenylenediamine hardener at a ratio by weight of 100:30. The carbon fibers unidirectional of $200 \mathrm{gsm}$ were used as main reinforcement in the matrix. The Montmorillonite nanoclay and Zinc Oxide nanoparticle was dried out for overnight at $75^{\circ} \mathrm{C}$ in an oven previous to use for compose suitable for spreading in epoxy resin. The nano particle content was preferred in between the $1 \%$ to $5 \%$ for mixing in the epoxy resin and hardener. For the making of specimens, 14-16 nos. plies were used according to ASTM standards; accordingly the sub specimens are cut of the required size. For executing the mixing of the particles uniformly in the resin mixture, the ultra sonication of the mixture was done for 40 minutes at $40^{\circ} \mathrm{C}$ temperature, and then this mixture is magnetically stirred with $800 \mathrm{rpm}$ for one and half hour. After completing the mixing treatment he hardener is mixed and this mixture is used for the preparation of the CFRO hybrid nanocomposites laminates by hand layup succeeded by process of vacuum bagging as shown in Fig.1. For process of vacuum bagging, pump was used for the period of 5 hours with a stable of $720 \mathrm{~mm} \mathrm{Hg}$ vacuum pressure. And the specimen was put in the bag for 16 hours duration of curing at room temperature. After the curing, specimen was kept in an oven for process of post curing for five hours at $80^{\circ}$.

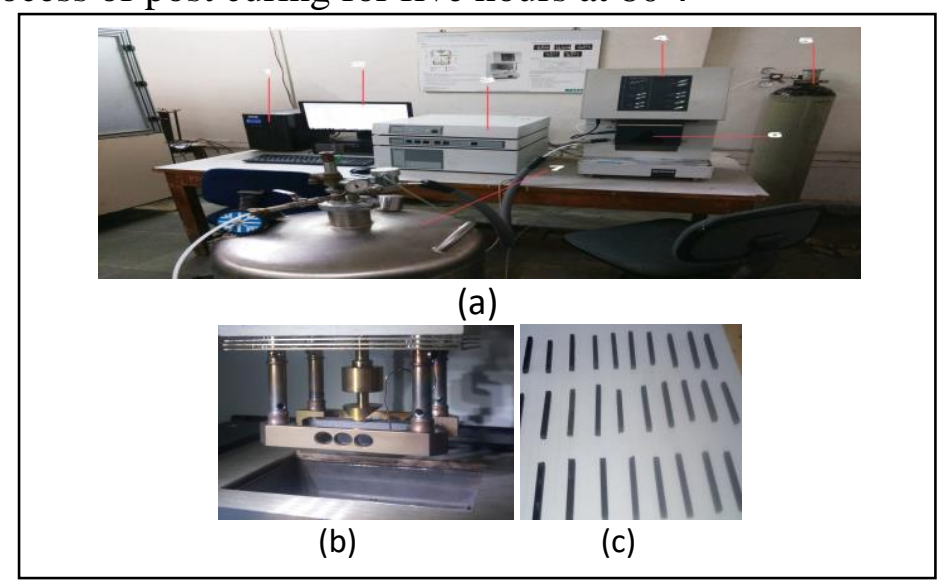

Figure 2: (a) DMA 242 E Artemis set up,(b) Specimen Holder in DMA setup, (c) Specimens of coded units 


\section{Dynamic Mechanical Analysis (DMA)}

DMA is an extensively used method to determine the effect of temperature on the properties of damping and various moduli of materials by application of sinusoidal force. Modulus is calculated in the 2 parts, these are storage modulus, E' and loss modulus, E". The relation of loss modulus to the storage modulus is known as mechanical damping (given by $\tan \delta$ is a dimensionless number) it gives the energy lost or can also be expressed in form of recoverable energy. The higher $\tan \delta$ value is indicates that material has higher non elastic strain, while lower $\delta$ shows that material is more elastic. Storage modulus elaborates the elastic behavior of the CFRP and which is proportionate to the energy stored in one cycle, while loss modulus gives the viscous properties of material, which is proportionate to energy dissipated in one cycle, The phase angle, $\delta$ which is the phase difference between the dynamic stress and strain of viscoelastic material under the effect of sinusoidal oscillation. This dynamic mechanical test is used to derive the viscoelastic and elastic behaviors of CFRP hybrid nanocomposites sample with the sinusoidal force application. The thermal analyses were completed by using a DMA242E analyzer (Netzsch, Germany) in a mode of three-point-bending with the oscillation of 1 $\mathrm{Hz}$ (as shown in Fig. 2.(a)). The storage modulus (E'), damping factor ( $\tan \delta$ ) and loss modulus (E") of each CFRP hybrid nanocomposite sample were determine under the subsequent conditions: a temperature range from $40^{\circ} \mathrm{C}$ up to $150^{\circ} \mathrm{C}$ at rate of heating of $3^{0} \mathrm{C} / \mathrm{min}$, as a cooling agent the liquid nitrogen is used by putting in the machine fixture (as shown in Fig. 2.(b). The samples were sized in $40 \mathrm{~mm}$ in length and $4 \mathrm{~mm}$ in width, while the thickness were around $3.2 \mathrm{~mm}$ (as shown in Fig. 2.(c).

\section{Experimental OVAT analysis and results}

The DMA test is carried out to study the various changes in thermal behaviour or viscoelastic properties of the CFRP hybrid composites. This experimental study highlights the effect of variable quantity of nano particles along with variation of the fiber orientation angle on the CFRP hybrid nano composites properties like storage modulus, GTT, Loss modulus etc. In the OVAT=I analysis by varying the weight percentage of nano zinc keeping nano clay percentage and fiber orientation angle constant the effect is studied. Then simultaneously OVAT-II and OVAT-III is carried out by varying the weight percentage of nano $\mathrm{ZnO}$ and fiber orientation angel. The results of DMA test are along with the controlled sample ie for plain CFRP composites as shown in Table 1 and Table 2.

Table 1: OVAT analysis values and controlled sample values of storage and loss modulus along with temp at loss modulus

\begin{tabular}{|c|c|c|c|c|c|}
\hline Sr. No & $\begin{array}{c}\text { Fiber } \\
\text { Angle }\end{array}$ & $\begin{array}{c}\% \text { of } \\
\text { Clay }\end{array}$ & $\begin{array}{c}\% \text { of } \\
\mathrm{ZnO}\end{array}$ & $\begin{array}{c}\text { Storage } \\
\text { Modulus } \\
\mathrm{MPa}\end{array}$ & $\begin{array}{c}\text { Peak Loss } \\
\text { Modulus/Temp } \\
\mathrm{MPa} /{ }^{\circ} \mathrm{c}\end{array}$ \\
\hline I-A & $0^{0}$ & 2 & 2 & 7122 & $1549 / 67.5$ \\
\hline I-B & $0^{0}$ & 2 & 3 & 4800.93 & $1128 / 70.9$ \\
\hline I-C & $0^{0}$ & 2 & 4 & 18197 & $3218 / 65.4$ \\
\hline II-A & $0^{0}$ & 2 & 2 & 5386 & $1265 / 66.2$ \\
\hline II-B & $0^{0}$ & 3 & 2 & 11899.54 & $1905 / 65.8$ \\
\hline II-C & $0^{0}$ & 4 & 2 & 5279.62 & $973 / 65.7$ \\
\hline III-A & $0^{0}$ & 2 & 2 & 7122 & $1549 / 67.5$ \\
\hline III-B & $45^{0}$ & 2 & 2 & 10282 & $2135 / 65.70$ \\
\hline III-C & $90^{0}$ & 2 & 2 & 3877 & $708 / 65.8$ \\
\hline PC & $0^{0}$ & 0 & 0 & 6428 & $2798 / 76.6$ \\
\hline
\end{tabular}


Table 2: OVAT analysis values and controlled sample values of Tan $\delta$ and Glass transition temperature (GTT)

\begin{tabular}{|c|c|c|c|c|c|}
\hline $\begin{array}{l}\text { Sr. } \\
\text { No }\end{array}$ & $\begin{array}{l}\text { Fiber } \\
\text { Angle }\end{array}$ & $\begin{array}{l}\% \text { of } \\
\text { Clay }\end{array}$ & $\begin{array}{l}\% \text { of } \\
\mathrm{ZnO}\end{array}$ & Tan $\delta$ & $\begin{array}{c}\text { GTTemp } \\
{ }^{0} \mathrm{c}\end{array}$ \\
\hline I-A & $0^{0}$ & 2 & 2 & 0.755 & 70.8 \\
\hline I-B & $0^{0}$ & 2 & 3 & 0.798 & 75.2 \\
\hline $\mathrm{I}-\mathrm{C}$ & $0^{0}$ & 2 & 4 & 0.758 & 69.9 \\
\hline II-A & $0^{0}$ & 2 & 2 & 0.808 & 69.8 \\
\hline II-B & $0^{0}$ & 3 & 2 & 0.767 & 70.5 \\
\hline II-C & $0^{0}$ & 4 & 2 & 0.661 & 71.1 \\
\hline III-A & $0^{0}$ & 2 & 2 & 0.755 & 70.8 \\
\hline III-B & $45^{0}$ & 2 & 2 & 0.787 & 70.6 \\
\hline III-C & $90^{\circ}$ & 2 & 2 & 0.634 & 71.5 \\
\hline PC & $0^{0}$ & 0 & 0 & 0.599 & 82.1 \\
\hline
\end{tabular}

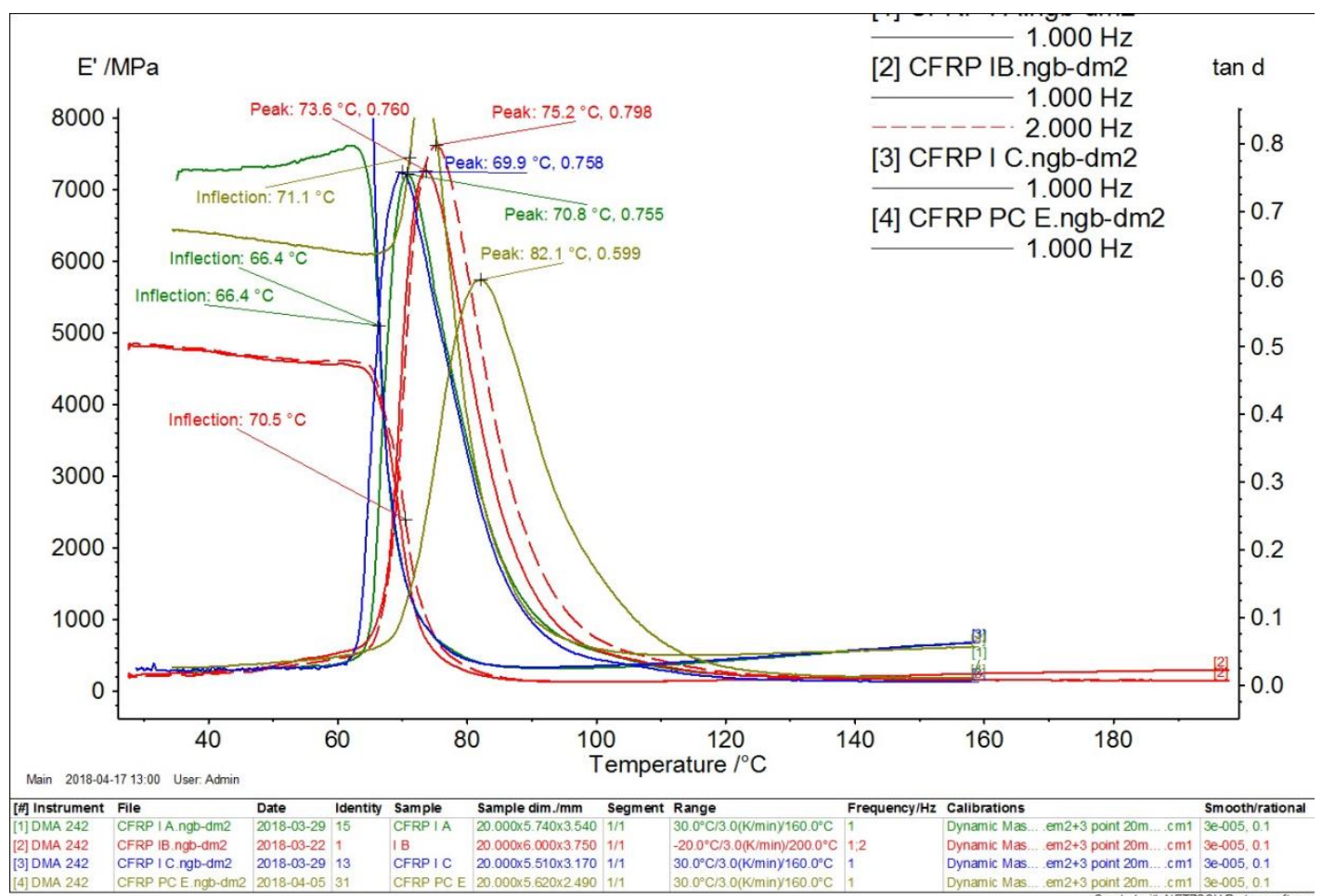

Figure 3: Showing the Storage modulus and GTT and Tan $\delta$ values of OVAT -I compared with plain CFRP sample

From the above figure No 3. This is the output of given directly by Dynamic mechanical test analyser. It can be understood that how there is drastic improvement in the value of storage modulus in the flexural test and also here is increase in the inflection temperature with the small decrease in GTT (Glass transmission temperature), as compared with the CFRP controlled sample. Similarly in the Figure 4. Showing the Loss modulus and temperature of OVAT-I,(in which the wt. \% of nano clay is kept constant) compared with plain CFRP sample, the loss modulus is also increasing than the controlled sample but it is desirable with due increase in the storage modulus. 


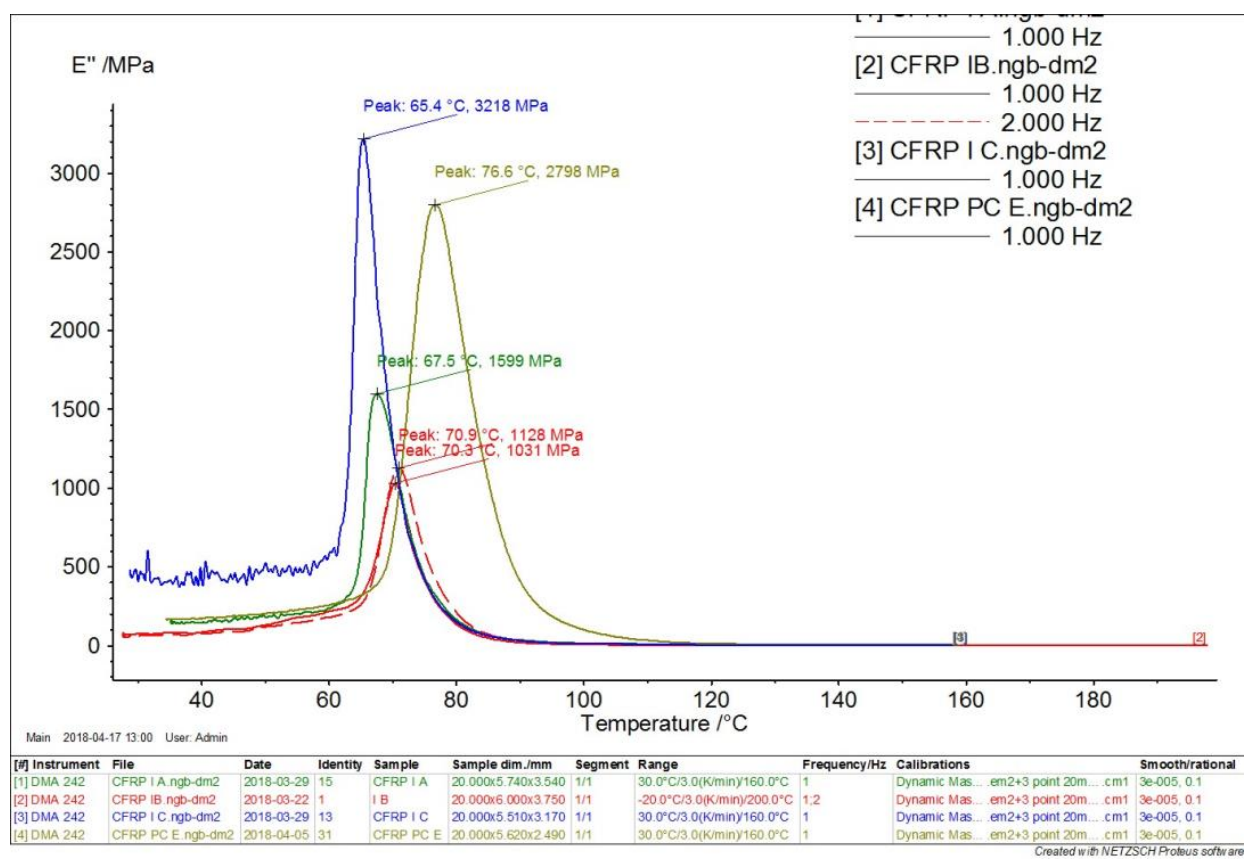

Figure 4: Showing the Loss modulus and temperature of OVAT-I compared with plain CFRP sample

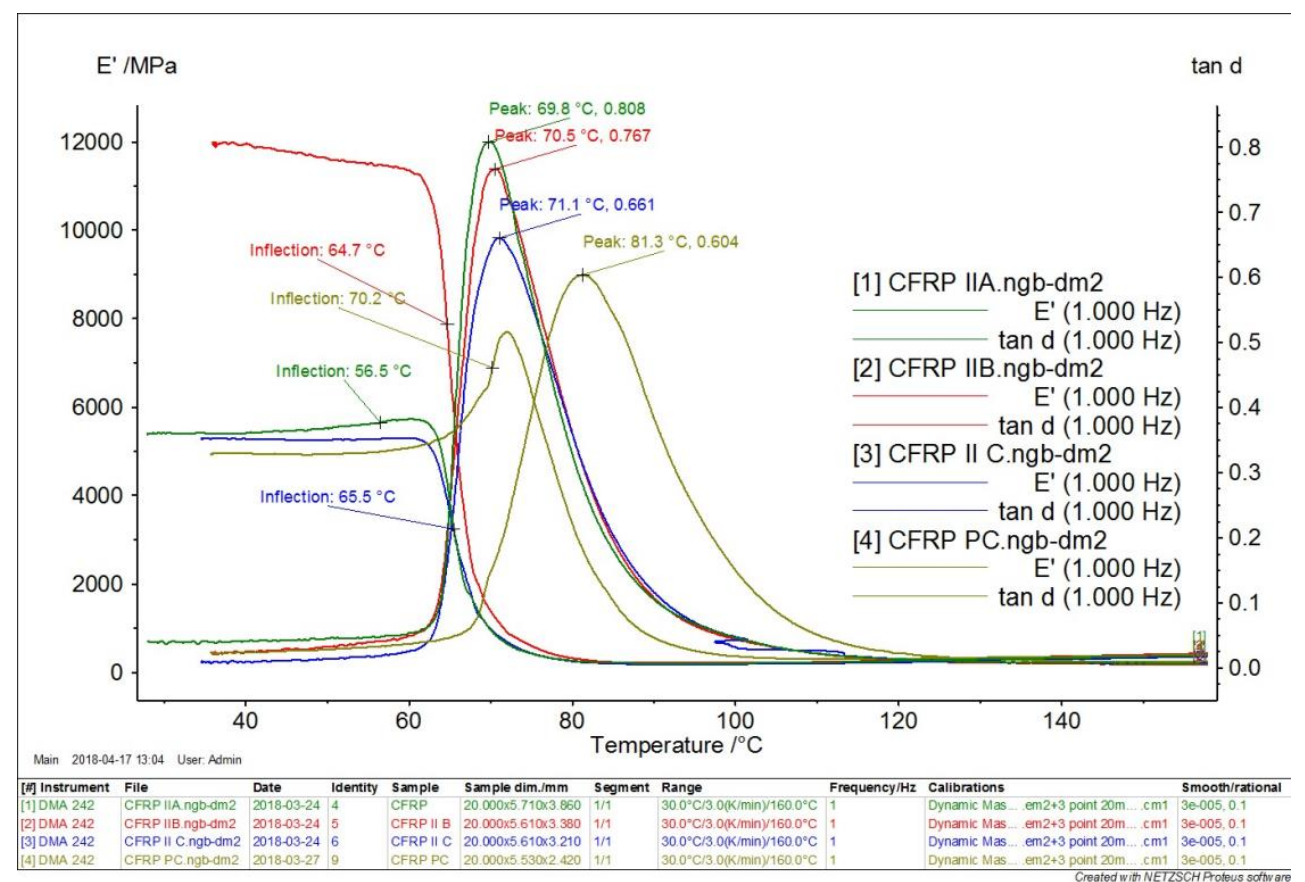

Figure 5: Showing the Storage modulus and GTT and Tan $\delta$ values of OVAT -II compared with plain CFRP sample

As shown in the figure 5, it can be seen that the in OVAT-II,(in which the wt. \% of nano $\mathrm{ZnO}$ is kept constant), the flexural storage modulus is almost doubled as compared with plain CFRP sample, with the small decrease in the GTT and considerable increase in the value of Tan $\delta$. And as reflected in the figure 6, Showing the Loss modulus and temperature of OVAT-II, compared with plain CFRP sample, the loss modulus is also increasing than the controlled sample but it is desirable with due increase in the storage modulus. 


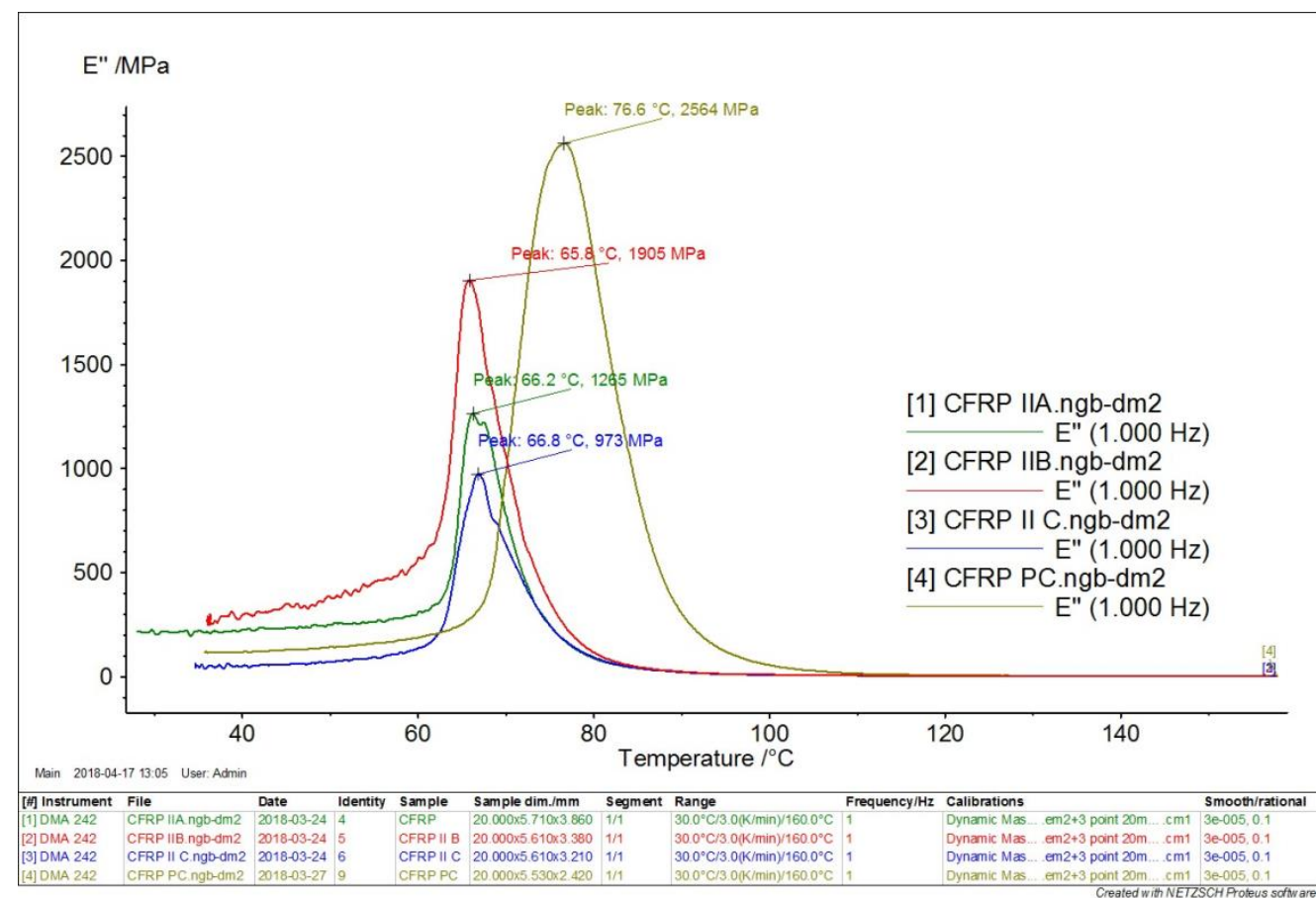

Figure 6: Showing the Loss modulus and temperature of OVAT-II compared with plain CFRP sample

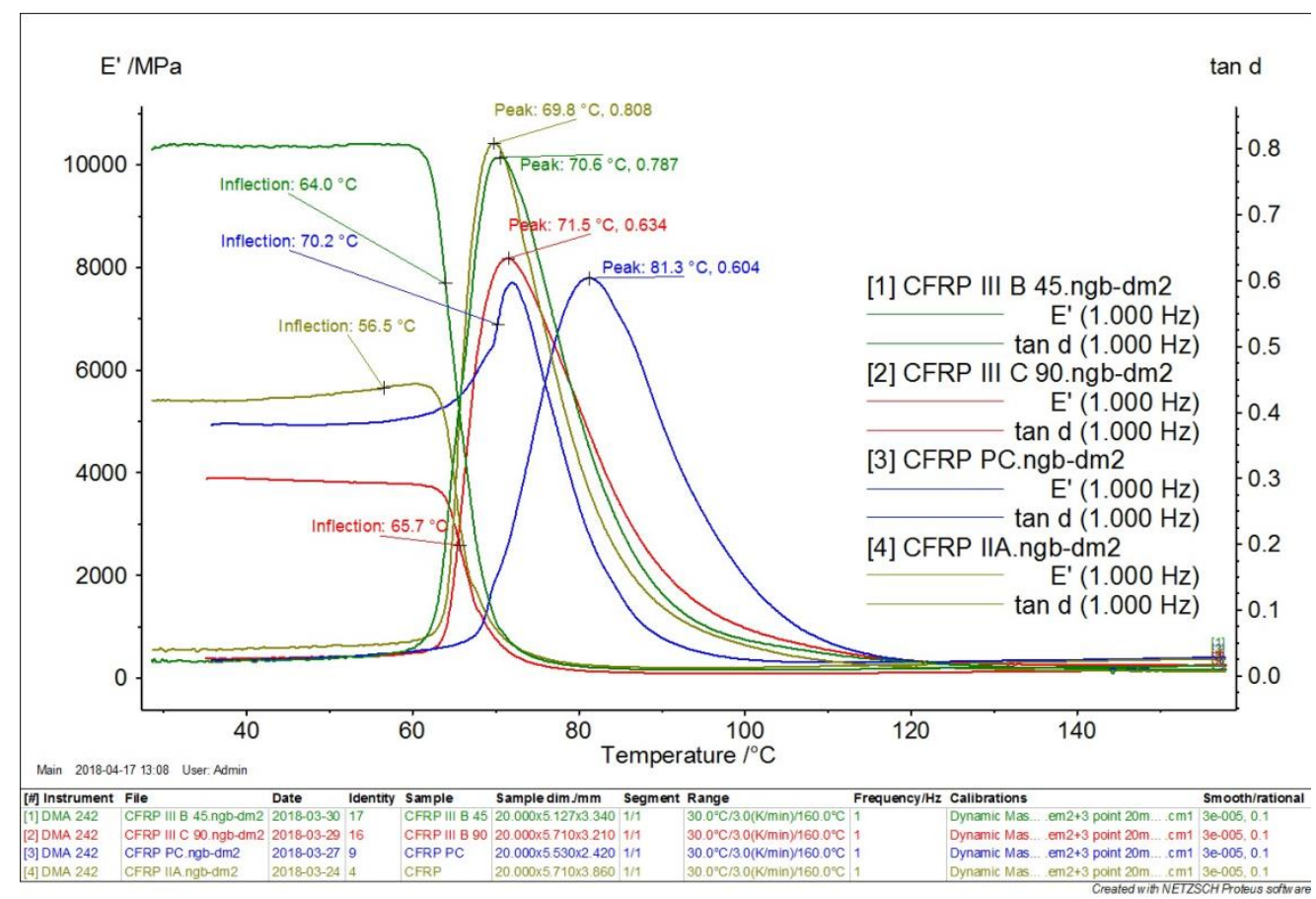

Figure 7: Showing the Storage modulus and GTT and Tan $\delta$ values of OVAT -II compared with plain CFRP sample

After the OVAT-II, There is variance of the fiber orientation angle in the OVATIII, by keeping the wt. Percentage of nano clay and nano $\mathrm{ZnO}$ constant. It is obtained from the dynamic mechanical analysis/test of CFRP hybrid nano composites with variance in the orientation angle and keeping the nanoparticle wt percentage at the value of $2 \%$ of both nano clay and nano $\mathrm{ZnO}$. The graph presents that more than double improvement in the storage modulus due to flexure as compared the controlled sample of CFRP. Also it 
shows that there is increase in the inflation temperature and the value of Tan $\delta$ (damping factor).

According to the graph in figure 8 , which gives the value of loss modulus with the change in temperature it can be seen that the peak value of temperature and loss modulus is high

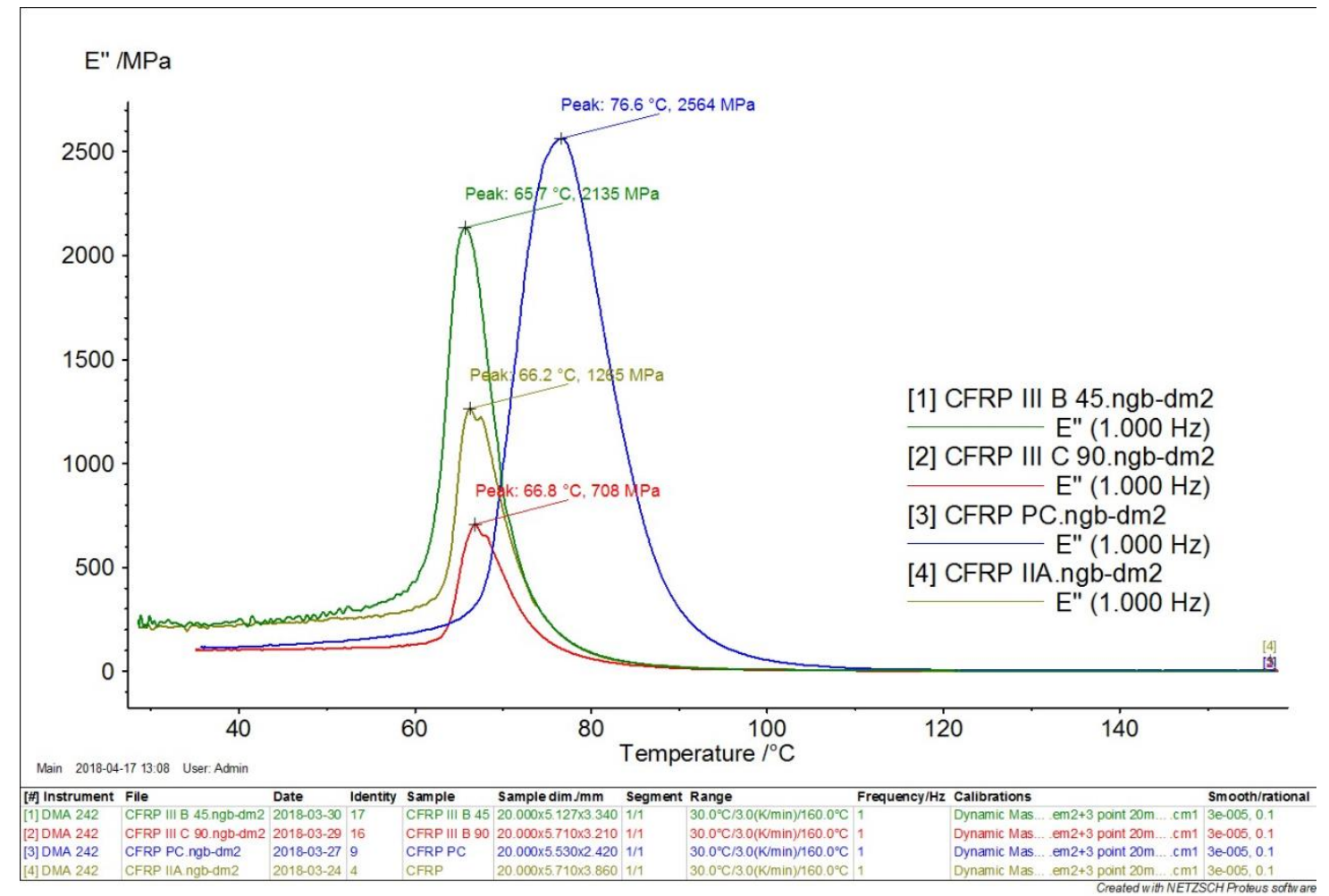

Figure 8: Showing the Loss modulus and temperature of OVAT-II compared with plain CFRP sample

For the controlled sample of CFRP as compared with the CFRP hybrid nanocomposite samples. Hence it is proved from the experimental analysis that along with the nano particle presence there is also effect of the change in fiber orientation angle on the visco elastic properties of CFRP composites.

\section{Conclusion}

Carbon fibre reinforced composites with and without nano particles were fabricated and tested for the dynamic mechanical analysis and visco elastic properties For dispersing nanoparticles in the epoxy system, a combination of sonication and magnetic stirring methods was used. For fabricating laminate composite, combination of hand layup and vacuum bagging methods was used. From the results of the tests it is concluded that the presence of the nano particles with varying their wt. Percentage in epoxy system of CFRP composites are having greater value around more than $200 \%$ is increased $t$ in the value of storage modulus due flexure and hence its having high loss factor too. There is also moderate change in the GTT and peak temperature of the CCFRP with nano particles. From the results of OVAT-III ,It is proved that there is also effect of change inthe fiber angle orientation on the visco elastic behaviour of the CFRP hybrid nano composites. Hence it is observed that there is definite enhancement in the CFRP composite because of the mixing of controlled wt. Of nano particles. Also fiber orientation angle is also having considerable effect on thermo mechanical properties of CFRP along with nanoparticles. 


\section{References}

[1] M.A. Shazed ,A.R.Suraya, S. Rahmanian, M.A. MohdSalleh., Effect of fibre coating and geometry on the tensile properties of hybrid carbon nanotube coated carbon fibre reinforced composite, Materials and Design $54,2014,660-669$.

[2] Rashmi ,N.M. Renukappa , B.Suresha , Dry sliding wear behaviour of organo-modified montmorillonite filled epoxy nanocomposites using Taguchi $\mathrm{s}$ techniques, Materials and Design 32 ,2011, 4528-4536.

[3] Li Chang, Klaus Friedrich, Enhancement effect of nanoparticles on the sliding wear of short fiber-reinforced polymer composites: A critical discussion of wear mechanisms, Tribology International $43,2010,2355-2364$.

[4] David A. Hawkins Jr., Anwarul Haque, Fracture toughness of carbon-graphene/epoxy hybrid Nan ocomposites- Procedia Engineering 90 ,2014, 176 - 181.

[5] Ayoub Yari Boroujeni, Marwan Al-Haik, Anahita Emami, and Roozbeh Kalhor, Hybrid ZnO Nanorod Grafted Carbon Fiber Reinforced Polymer Composites Composites; Randomly versus Radially Aligned Long $\mathrm{ZnO}$ Nanorods Growth- Journal of Nanoscience and Nanotechnology Vol. 18, No.6, 4182-4188, 2017.

[6] Chuanbao Wang and SanjiuYing,Thermal, Tensile and Dynamic Mechanical Properties of ShortCarbon Fibre Reinforced Polypropylene Composites, Polymers \& Polymer Composites, Vol. 21, No. 2, 2013.

[7] Suma Ayyagari, et al. Mechanical and Electrical Characterization of CarbonFiber/Bucky Paper/Zinc Oxide Hybrid Composites, Journal of Carbon Research,C 2018, 4, 6; doi:10.3390/c4010006.

[8] Michelle LealiCosta, Edson CocchieriBotelhoa, Jane Maria Faulstich de Paivaa, Mirabel CerqueiraRezendea*, Characterization of Cure of Carbon/Epoxy Prepreg Used in Aerospace Field, Materials Research, Vol. 8, No. 3, 317-322, 2005.

[9] D. Kaka1, J. Rongong2, A. Hodzic3, C. Lord, Dynamic mechanical properties of woven carbon fibre reinforced thermoplastic composite materials, university of Sheffield http:// eprints. whiterose.ac.uk/96135.

[10] Dana Luca Motoc1, Santiago Ferrandiz Bou2 andRafael Balart Gimeno, Effects of fibre orientation and content on the mechanical, dynamic mechanical and thermal expansion properties of multi-layered glass/carbon fibre-reinforced polymer composites, Journal of Composite Materials2015, Vol. 49(10) 1211-1221.

[11] Sandi G. Miller, Paula J. Heimann and Daniel A. Scheiman, Evaluation of Nanomaterial Approaches to Damping in Epoxy Resinand Carbon Fiber/Epoxy Composite Structures byDynamic Mechanical Analysis, NASA/TM-2013-217887

[12] MohamedH.Gabr, WataruOkumura, HisaiUeda, WataruKuriyama, KiyoshiUzawa, IsaoKimpara, Mechanical and thermal properties of carbon fiber/polypropylene composite filled with nano-clay, Composites: Part B 69 ,2015, 94-100.

[13] Declan Carolana, A.J.Kinlocha, A.Ivankovicb, S. Sprengerc, A.C. Taylora., Mechanical and fracture performance of carbon fiber reinforced composites with nanoparticle modified matrices, Procedia Structural Integrity 02 , 2016, 096-103.

[14] M.B.A.Salam, M.V.Hosur, S. Zainuddin, S. Jeelani, Improvement in Mechanical and Thermo-Mechanical Properties of Epoxy Composite Using Two Different Functionalized Multi-Walled Carbon Nanotubes, Open Journal of Composite Materials, 2013, 3, 1-9.

[15] M.B.A. Salam, M.V. Hosurb, N. Jahana, M.M. Rahmana, and S. Jeelania, Improvement in Mechanical and Thermo-Mechanical Propertiesof Carbon fibre/Epoxy Composites Using Carboxyl Functionalized Multi-Walled Carbon Nanotubes, Polymers \& Polymer Composites, Vol. 21, No. 8, 2013.

[16] Sasan Nouranian, Hossein Toghiani, Thomas E. Lacy,Charles U. Pittman, Jr.Janice Dubien, Dynamic mechanical analysis and optimization of vapor-grown carbon nanofiber/vinyl ester nanocomposites using design of experiments, Journal of Composite Materials, 45(16) 16471657.

[17] V.K.Tripathi, N.S.Kulkarni, OptiComp: A Comprehensive Procedure for Optimal Design of a Composite Laminate, Int.J. of Engg. Sciences, Vol. 8(2), 2014, pp. 110 -120. 
[18] Optimization of compressive strength of zirconia based dental composites, U. V. Hambire, V.K. Tripathi, Bull. Mater. Sci., Vol. 37(6), 2014, pp. 1315-1320 .

[19] Experimental evaluation of different fillers in dental composites in terms of mechanical properties', U. V. Hambire and V. K. Tripathi, ARPN Journal of Engineering and Applied Sciences, Vol. 7(2), 2012, pp. $147-151$.

[20] V. K. Tripathi, A.J. Mathews, P.K Pandey , A systematic procedure to find optimum composition of the material used for friction liners of trucks'., Int. Journal of Engineering Sciences, 1 (1), pp. $39-54,2010$.

[21] Volker Itsta, PhilippWerner, JanSandler, Rheological, Mechanical and Tribological Properties of Carbon-nanofibre Reinforced Poly (ether ether ketone) Composites, Polímeros: Ciência e Tecnologia, vol. 13, $\mathrm{n}^{\circ}$ 4, p. 218-222, 2003

[22] P. SuryaNagendra1, V.V.S. Prasad1, KoonaRamji, A Study on Dynamic Mechanical Analysis of Natural Nano Banana Particle Filled Polymer Matrix Composites, Materials Today: Proceedings 4, 2017, 9081-9086

[23] Hariharasudhan S1, Balaji A P2, Sathishkumar K S3, Yuvaraj K4, Mechanical Behavior and Dynamic Mechanical Analysis Study on Nanoclay Filled Carbon-Epoxy Composites, IJIRSTE, Volume 5, Special Issue 7, April 2016

[24] Yasser Rostamiyan ,AbdolhosseinFereidoon, etal. Using response surface methodology for modeling and optimizing tensile and impact strength properties of fiber orientated quaternary hybrid nano composite, Composites: Part B 69, 2015, 304-316.

[25] Y. Rostamiyan, A. Fereidoon, Experimental study and optimization of damping properties of epoxy-based nanocomposite: Effect of using nanosilica and high-impact polystyrene by mixture design approach, Materials and Design 65, 2015, 1236-1244

[26] Rostamiyan, Abdolhosein Fereidoon, et al, Experimental and optimizing flexural strength of epoxy-based nanocomposite: Effect of using nano silica and nano clay by using response surface design methodology, Materials and Design 69, 2015, 96-104.

[27] R. Satheesh Raja, K.Manisekar, Experimental and statistical analysis on mechanical properties of nano fly ash impregnated GFRP composites using central composite design method, Materials and Design 89, 2016, 884-892. 